\title{
WEIGHTS OF CARDIAC VENTRICLES AT AND AFTER BIRTH
}

\author{
BY \\ JOHN L. EMERY AND AVINASH MITHAL \\ From the Department of Pathology, Children's Hospital, Sheffield
}

Received November 8, 1960

Opinion has been divided on the ventricular weight preponderance of the heart at birth. Spigelius (1626) and William Harvey (1628) considered the ventricles equal; Müller (1883) mentioned the right as being less; and Patten (1930) found that the right outweighed the left by 8:7. There is also a difference of opinion regarding right ventricular weights after birth. Müller (1883) demonstrated a post-natal physiological "atrophy". Brock (1932) considered that there was normal weight gain, and lately Keen (1955) has again found a post-natal "atrophy", maximal at two months.

We have recently demonstrated (Macdonald and Emery, 1960) that the fœtus up to the age of approximately 30 weeks has a heart with left ventricular preponderance. This is reversed in later intrauterine life, but apparently again begins to revert towards left ventricular preponderance during the last few weeks before full term.

The present study is an attempt to determine the weights of the right and left ventricles of the normal full-term infant following birth and during infancy.

\section{MATERIAL AND MethodS}

Over a thousand hearts from live-born children of all ages were available for study. These hearts came from necropsies carried out by the Department of Pathology at the Children's Hospital, Sheffield. From this material a careful selection was made, eliminating all cases in which there was

(i) any suspicion of cardio-pulmonary pathology or deformity,

(ii) uncertainty as to full-term gestation age at birth,

(iii) congenital deformity of other systems of the body,

(iv) fibrocystic disease of the pancreas (because of the possibility of phases of lung infection producing pulmonary heart disease),

(v) hydrocephalus, brain tumours, or kidney disease (because of the possibility of consequent hypertension), or

(vi) any disease of long standing or producing general wasting.

At the time the selection was made the ventricular weights were not known. The exclusion of these groups left 105 cases for study. These were all of 40 weeks gestation at birth: in none of them was there any suspicion of primary or secondary abnormality.

The method of dissection of the right and left ventricles was the same as that used for investigating weights in stillborns (Emery and Macdonald, 1960), a method essentially the same as that previously described by Lewis (1914) and Hermann and Wilson (1922). At the time of dissection the age and history of the case were not known. Studies were also made of a large number of hearts from children suffering from a great variety of diseases. The results of these were not used in the present work. 


\section{RESULTS}

The weights of the left and right ventricles with standard deviations are shown in Table I. The weights of the right ventricle are given in scattergrams against post-natal age (Fig. 1) and crownrump age (Fig. 2). In these figures three points representing Cases $\mathbf{A}, \mathbf{B}$, and $\mathbf{C}$ were later inserted.

TABLE I

Post-natal Ventricular Weights in 105 Infants and Children

\begin{tabular}{|c|c|c|c|c|c|c|}
\hline \multirow[t]{2}{*}{ Age range } & \multirow[t]{2}{*}{ Mean age } & \multirow[t]{2}{*}{ No. of cases } & \multicolumn{2}{|c|}{ Left ventricle } & \multicolumn{2}{|c|}{ Right ventricle } \\
\hline & & & $\begin{array}{c}\text { Mean } \\
\text { wt. (g.) }\end{array}$ & S.D. & $\begin{array}{c}\text { Mean } \\
\text { wt. (g). }\end{array}$ & S.D. \\
\hline $\begin{array}{c}\text { Birth }(40 \mathrm{wks}) \\
15 \mathrm{~d} .-1.4 \mathrm{~m} . \\
1.4 \mathrm{~m} .-2.2 \mathrm{~m} . \\
2.2 \mathrm{~m} .-3.4 \mathrm{~m} . \\
3.4 \mathrm{~m} .-9 \mathrm{~m} . \\
9 \mathrm{~m} .-1.1 \mathrm{yr} . \\
1.1 \mathrm{yr}-1.6 \mathrm{yr} . \\
1.6 \mathrm{yr} .-2.5 \mathrm{yr} . \\
2.5 \mathrm{yr} .-5 \mathrm{yr} . \\
5 \mathrm{yr} .8 .4 \mathrm{yr} . \\
8.4 \mathrm{yr} .-13 \mathrm{yr} .\end{array}$ & $\begin{array}{l}28 \overline{\mathrm{d}} . \\
1.62 \mathrm{~m} . \\
2.81 \mathrm{~m} . \\
5.29 \mathrm{~m} . \\
10.24 \mathrm{~m} . \\
1.3 \mathrm{yr} . \\
1.9 \mathrm{yr} . \\
3.6 \mathrm{yr} . \\
6.6 \mathrm{yr} . \\
10.1 \mathrm{yr} .\end{array}$ & $\begin{array}{r}11 \\
9 \\
12 \\
9 \\
12 \\
10 \\
8 \\
8 \\
9 \\
8 \\
9\end{array}$ & $\begin{array}{r}5 \cdot 8 \\
8 \cdot 8 \\
9 \cdot 8 \\
13 \cdot 7 \\
16 \cdot 5 \\
18 \cdot 2 \\
21 \cdot 5 \\
26 \cdot 0 \\
30 \cdot 2 \\
47 \cdot 6 \\
62 \cdot 2\end{array}$ & $\begin{array}{r}1 \cdot 16 \\
2 \cdot 38 \\
2 \cdot 55 \\
2 \cdot 33 \\
3 \cdot 62 \\
3 \cdot 69 \\
4 \cdot 21 \\
4 \cdot 07 \\
6 \cdot 80 \\
12 \cdot 65 \\
15 \cdot 00\end{array}$ & $\begin{array}{r}6 \cdot 6 \\
6 \cdot 5 \\
7 \cdot 1 \\
7 \cdot 6 \\
9 \cdot 5 \\
12 \cdot 0 \\
12 \cdot 0 \\
17 \cdot 3 \\
18 \cdot 1 \\
29 \cdot 9 \\
35 \cdot 0\end{array}$ & $\begin{array}{r}1 \cdot 46 \\
1.73 \\
1.93 \\
0 \cdot 80 \\
2 \cdot 32 \\
2.02 \\
4 \cdot 30 \\
6 \cdot 23 \\
3.74 \\
7 \cdot 13 \\
11.96\end{array}$ \\
\hline
\end{tabular}

\section{RIGHT VENTRICLE WEIGHT AFTER BIRTH}

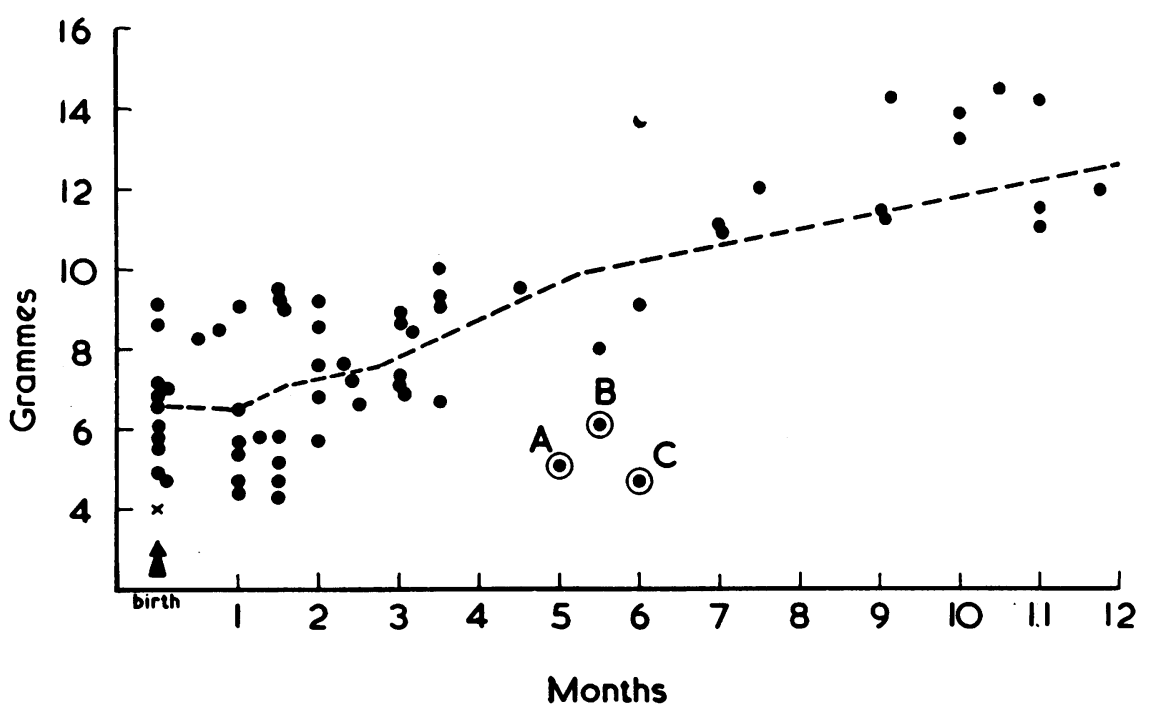

Fig. 1.-Scattergram giving the weights of the right ventricle related to months after birth. Inserted ringed points $A, B$, and $C$ represent ill children. $A$ and $B$ died in a wasted state with fibrocystic disease and Case $\mathrm{C}$, a full-term child, dying at the age of six months and weighing only $10 \mathrm{lb} .2 \mathrm{oz}$.

Cases A and B were full-term children dying in a wasted state from "fibrocystic disease" and Case $\mathrm{C}$ was a full-term child dying at the age of six months with a body weight of only $10 \mathrm{lb} .2 \mathrm{oz}$. 
RIGHT VENTRICLE WEIGHT AFTER BIRTH

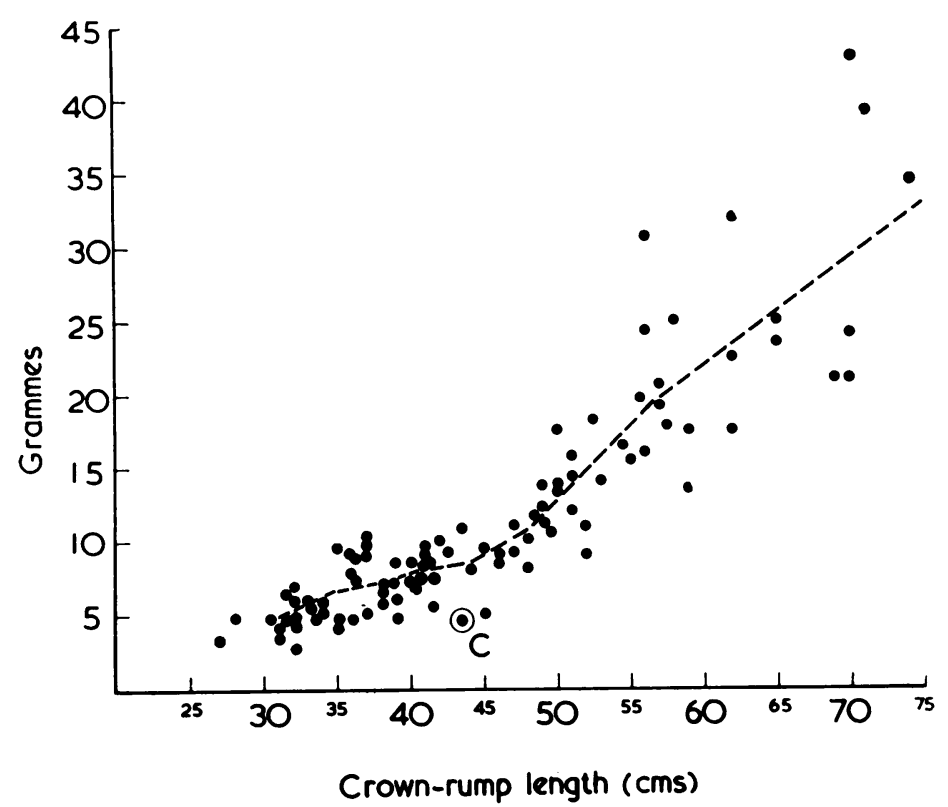

FIG. 2.- The weight in grammes of the right ventricle in children dying after birth who were fully mature at birth related to crown-rump length. Point $\mathrm{C}$ is the same child as case $\mathrm{C}$ in Fig. 1.

Ventricular Preponderance at Birth. The mean weight of the left ventricle at birth was 5.7 (S.D. $1 \cdot 1)$ and of the right $6 \cdot 6$ g. (S.D. 1 4 ). These figures must be considered in conjunction with those found in stillborns dying at less than 40 weeks gestation (Emery and Macdonald, 1960). In stillborn children near term the right ventricle outweighs the left: this is true for the later stages of pregnancy also, assessed against crown-rump length or body weight. Brock (1932) accepted Müller's (1883) figures uncritically (as noted by Keen (1955)) and stated that the left ventricle outweighs the right at birth. Patten (1930) studying hearts from 50 stillborn children of unspecified gestation also found the right ventricle to be heavier than the left but did not give the details of his method.

The Age at which the Left Ventricle Finally Outweighs the Right. In the present study it was observed that the left ventricle outweighed the right within four weeks of birth. This result agrees with Keen's (1955) finding that there was left ventricular preponderance after the age of one month.

Post-Natal Right Ventricular Growth. In the present series the mean weight of the right ventricle at birth was 6.6 g. (S.D. 1.4), at one month 6.4 g. (S.D. 1.7), and at six weeks 7.1 g. (S.D. 1.9). But statistically the difference between the weight at birth and at four and six weeks is not significant. The picture obtained from the scattergram (Fig. 1) is of a general increase in weight with a wide scatter of cases at the age of about one month. When the same cases are charted against crown-rump length the scatter is less and the weight increase much more obvious and uniform. There would thus seem to be no evidence for atrophy of the right ventricle after full-term birth. We have shown elsewhere in studies of children born prematurely (Mithal and Emery, 1960) that the right ventricle continues to gain weight at the same rate as if the child had remained 
in utero. Under the same circumstances the left ventricle increases more rapidly. These facts indicate that there is no post-natal atrophy following premature birth.

The reason why different conclusions have been drawn by earlier workers is not difficult to see. We have shown elsewhere that the very immature infant at a weight below $1000 \mathrm{~g}$. or of only 32 weeks gestation has a heart with left ventricular preponderance similar to that in the adult. Thus if stillborn infants and neonates of variable gestation age were grouped together, no significant average result would be obtained. General body weight and growth remain the most important features. The inclusion of wasted or abnormal infants would have caused the average weight to fall considerably. This is illustrated by Cases A, B, and C inserted in Fig. 1 and 2. This effect of wasting is known to occur in adult hearts (Levin and Carr, 1933), a circumstance that probably affected Keen's (1955) results. He mentioned that most infants in his series were so wasted as to render valueless the body weight as a criterion of maturity.

\section{SUMMARY AND CONCLUSIONS}

From 1000 infant hearts, after excluding prematurely born infants or those dying with chronic illnesses, 105 were considered suitable for the study of normal ventricular weight.

At birth the right ventricle is found to outweigh the left. The left ventricle outweighs the right by the end of four weeks after birth.

No evidence for post-natal atrophy of the right ventricle was found. The right ventricle gains weight but at a slower rate than the left.

\section{REFERENCES}

Brock, J. (1932). Biologische Daten fur den Kinderarzt. Berlin, J. Springer, 132.

Emery, J. L., and Macdonald, M. S. (1960). Brit. Heart J., 22, 563.

Harvey, W. (1628). Exercitatio Anatomica de Motu Cordis et Sanguinis in Animalibus. Franoforti, Sumptibus, Guileimi Fitzeri.

Hermann, G. R., and Wilson, F. N. (1922). Heart, 9, 91.

Keen, E. N. (1955). J. Anat., 89, 484.

Levin, V., and Carr, J. G. (1933). Arch. intern. Med., 52, 429.

Lewis, T. (1914). Heart, 5, 367.

Mithal, A., and Emery, J. L. (in press).

Müller, W. (1883). Die Massenverhaltnisse des Menschlichen Herzens. Hamburg und Leipzig: Leopold Voss.

Patten, B. M. (1930). Amer. Heart J., 6, 192.

Spigelius, A. (1626). Quoted by Franklin, K. J. (1941). Ann. Sci., 5, 57. 